\title{
A New Approach of Principal Component Regression Estimator with Applications to Collinear Data
}

\author{
${ }^{1}$ Kayode Ayinde, ${ }^{2}$ Adewale F. Lukman, ${ }^{1}$ Olusegun. O. Alabi and ${ }^{1}$ Hamidu A. Bello \\ ${ }^{I}$ Department of Statistics, Federal University of Technology, Akure, Nigeria. \\ ${ }^{2}$ Department of Physical Sciences, Landmark University, Omu-Aran, Nigeria.
}

ORCID: 0000-0002-2993-6203 (Hamidu A. Bello), ORCID: 0000-0003-2881-1297 (Lukman)

\begin{abstract}
In this paper, a new approach to estimating the model parameters in Principal Components (PCs) is developed. Principal Component Analysis (PCA) is a method of variable reduction that has found relevance in combating multicollinearity problem in Multiple Linear Regression Models. In this paper, a new approach to estimating the model parameters in Principal Components (PCs) is developed The method requires using the PCs as regressors to predict the dependent variable and further utilizing the predicted variable as a dependent variable on the original explanatory variables in an Ordinary Least Square (OLS) regression. The resulting parameter estimates are the same as the estimates from the usual Principal Components Regression Estimator. The sampling properties of the new estimator are proved to be same as the existing ones. The new approach is simpler and easier to use. Real-life data sets are used to illustrate both the conventional and the developed method.
\end{abstract}

Keywords: Multiple Linear Regression Models, Multicollinearity, Principal Components, Ordinary Least Square

\section{INTRODUCTION}

Violation of independence of explanatory variables in multiple linear regression models results in multicollinearity problem (Gujarati, 2005). Literature has reported the use of the Ordinary Least Square (OLS) Estimator in the presence of multicollinearity with consequences. It does produce unbiased but inefficient estimates of the model parameters, estimates of regression coefficients having wrong signs and high standard deviation, and the parameter estimates and their standard errors become extremely sensitive to slight changes in the data points (Chatterjee and Hadi, 2006; Lukman et al., 2018; Ayinde et al., 2018). This consequence tends to inflate the estimated variance of the predicted values (Fomby et al., 1984; Maddalla, 1988; Ayinde et al., 2015).

Several other techniques are in use to combat this problem, and Principal Components Analysis (PCA) is one. It is a multivariate technique developed by Hotelling (1933) for explaining a set of correlated variables by a reduced number of uncorrelated ones with maximum variances called Principal components (PCs) (Naes and Marten, 1988; Chatterjee and Hadi, 2006). Other methods range from this method to more specialized techniques for regularization (Naes, and Marten, 1988). The PCR method has been proposed as alternatives to the OLS estimator when the independent assumption has not been satisfied in the analysis (Massy, 1965; Lee et al., 2015).

\section{LITERATURE REVIEW}

Consider the standard linear regression model defined as:

$$
y_{i}=\beta_{0}+\beta_{1} x_{i 1}+\beta_{2} x_{i 2}+\ldots+\beta_{p} x_{i p}+u_{i} \quad i=1,2, \ldots, n
$$

and defined in matrix form as

$$
y=X \beta+u
$$

where $y$ is $(n \times 1)$ vector for the observations of dependent variable; $X$ is $(n \times p)$ matrix of the observations of explanatory variables, $\beta$ is $(p \times 1)$ vector of regression coefficients $u$ is $(n \times 1)$ vector of the error terms assumed to multivariate normal distribution with mean zero and variance, $\sigma^{2} I_{n}$. Thus, the parameters of the model can be estimated using the use of Ordinary Least Square (OLS) estimator obtained as:

$$
\hat{\beta}_{O L S}=\left(X^{1} X\right)^{-1} X^{1} y
$$

The unbiased variance-covariance matrices of the OLS estimator can also be given as:

$$
\operatorname{Var}\left(\hat{\beta}_{O L S}\right)=\hat{\sigma}^{2}\left(X^{1} X\right)^{-1}
$$

where $\hat{\sigma}^{2}=\frac{\sum_{i=1}^{n}\left(y_{i}-\hat{y}_{i}\right)^{2}}{n-p},($ Maddalla, 1988; Kibra, 2003).

Lukman et al. (2020) reported the OLS estimator as Best Linear Unbiased Estimator (BLUE) provided there is no multicollinearity among the explanatory variables is not perfect. However, the estimator is still not efficient when there is multicollinearity (Chatterjee and Price, 1977; Gujarati, 
2005; Lukman et al., 2019; Lukman et al., 2020). Among the estimators commonly used to address this problem are the estimator based on Principal Component Regression developed by Massy (1965), the Ridge Regression (RRE) Estimator (Hoerl and Kennard, 1970), estimator based on Partial Least Square (PLS) Regression (Wold, 1985), and Liu estimator (Liu, 1993) and recently, the KL estimator by Kibria and Lukman (2020).

Estimator based on Principal Component Regression requires reducing the explanatory variables into a smaller number of summary variables often called Principal Components (or factors) that explain most of the variations in the data. According to Chatterjee and Price (1977), they summarized the algorithm of the procedures using the correlation matrices as follows:

i. Standardize both the response and the explanatory variables: The standardized variables respectively become:

$$
y_{i}^{1}=\frac{y_{i}-\bar{y}}{s_{y}}
$$

where $\bar{y}=\frac{\sum_{i=1}^{n} y_{i}}{n}$ and $s_{y}=\sqrt{\frac{\sum_{i=1}^{n}\left(y_{i}-\bar{y}\right)^{2}}{n=1}}$

where $\bar{x}_{j}=\frac{\sum_{i=1}^{n} x_{i j}}{n}$ and $s_{x_{j}}=\sqrt{\frac{\sum_{i=1}^{n}\left(x_{i j}-\bar{x}_{j}\right)^{2}}{n=1}}$

for $\mathrm{j}=1,2,3, \ldots, \mathrm{p}$

ii. Obtain the correlation matrices of the explanatory variables, say R. Thus,

$$
R=\left[\begin{array}{cccccccc}
1 & r_{12} & r_{13} & r_{14} & \cdot & \cdot & \cdot & r_{1 p} \\
r_{12} & 1 & r_{23} & r_{24} & . & . & \cdot & r_{2 p} \\
r_{13} & r_{23} & 1 & r_{34} & \cdot & \cdot & \cdot & r_{3 p} \\
r_{14} & r_{24} & r_{34} & 1 & \cdot & \cdot & \cdot & r_{4 p} \\
\cdot & \cdot & \cdot & \cdot & \cdot & \cdot & \cdot & \cdot \\
\cdot & \cdot & \cdot & \cdot & \cdot & \cdot & \cdot & \cdot \\
\cdot & \cdot & \cdot & \cdot & \cdot & \cdot & \cdot & \cdot \\
r_{1 p} & r_{2 p} & r_{3 p} & r_{4 p} & \cdot & \cdot & \cdot & 1
\end{array}\right]
$$

$$
\text { where } r_{j k}=\frac{\sum_{i=1}^{n}\left(x_{i j}-\bar{x}_{j}\right)\left(x_{i k}-\bar{x}_{k}\right)}{\sqrt{\left(\sum_{i=1}^{n}\left(x_{i j}-\bar{x}_{j}\right)^{2}\right)\left(\sum_{i=1}^{n}\left(x_{i k}-\bar{x}_{k}\right)^{2}\right)}} \text {, }
$$

$\mathrm{j}=1,2,3, \ldots, p ; \mathrm{k}=1,2,3, \ldots, p$

iii. Calculate the Eigenvalues and hence the Eigenvectors of the correlation matrices, say W. These become the coefficients (weights) that are attached to the standardized explanatory variables. Thus,

$$
W=\left[\begin{array}{cccccccc}
w_{11} & w_{12} & w_{13} & w_{14} & . & \cdot & \cdot & w_{1 p} \\
w_{21} & w_{22} & w_{23} & w_{24} & . & . & \cdot & w_{2 p} \\
w_{31} & w_{32} & w_{33} & w_{34} & \cdot & \cdot & \cdot & w_{3 p} \\
w_{41} & w_{42} & w_{43} & w_{44} & . & \cdot & \cdot & w_{4 p} \\
\cdot & \cdot & \cdot & \cdot & \cdot & \cdot & \cdot & \cdot \\
\cdot & \cdot & \cdot & \cdot & \cdot & \cdot & \cdot & \cdot \\
\cdot & \cdot & \cdot & \cdot & \cdot & \cdot & \cdot & \cdot \\
w_{1 p} & w_{2 p} & w_{3 p} & w_{4 p} & \cdot & \cdot & \cdot & w_{p p}
\end{array}\right]
$$

iv. Obtain the Principal Components (PCs) using the linear equation given as:

$$
P C_{i j}=\sum_{k=1}^{p} w_{k j} x_{i k}^{1}, \mathrm{i}=1,2, \ldots, \mathrm{n} ; \mathrm{j}=1,2, \ldots, \mathrm{p}
$$

These PCs are p orthogonal variables.

v. Determine the number of PCs to use: There is a need to determine the number of PCs to use. Since there are $p$ of them and using all of them will produce the same results with OLS. Hence a particular number of them has to be chosen. Kaiser (1960) suggested the use of PCs whose Eigenvalue is more than one. Constantin (2014) suggested using any component that accounts for at least $5 \%$ or $10 \%$ of the total variance. Some other authors emphasized that components should be selected enough so that the cumulative per cent of variance accounted for is so high, between $80 \%$ and $90 \%$ (Naes and Marten, 1988; Ali and Robert, 1998; Abdul-Wahab et al., 2005).

vi. Run the OLS regression (without intercept) of the standardized dependent variable on the selected $\mathrm{m}$ PCs. Thus,

$$
y_{i}^{1}=f\left(P C_{1}, P C_{2}, \ldots, P C_{m}\right)
$$

and obtain the estimates of the regression coefficients as $\hat{\gamma}_{1}, \hat{\gamma}_{2}, \ldots, \hat{\gamma}_{m}$. 
vii. Obtain the true regression coefficients of the linear model (2.1 or 2.2) based on Principal Component Regression method using:

$$
\widehat{\beta}_{P C R_{j}}=\frac{s_{y}}{s_{x_{j}}}\left[\sum_{t=1}^{m} w_{j t} \widehat{\gamma}_{t}\right] \mathrm{j}=1,2, \ldots, \mathrm{p}
$$

Also, the intercept can be obtained using:

$$
\widehat{\beta}_{P C R_{0}}=\bar{y}-\sum_{j=1}^{p} \widehat{\beta}_{P C R_{j}} \bar{x}_{j}
$$

Alternatively, re-consider model (2.2) again. Then, $X^{1} X$ becomes a $(p \times p)$ matrix whose Eigenvectors result into $(p \times p)$ orthogonal matrix $T=\left(t_{1}, t_{2}, \ldots t_{p}\right)=\left\lfloor T_{r}, T_{p-r}\right\rfloor$. Utilizing this and following the study of Ozkale (2009), Batah et al. (2009), and Chang and Yang (2012), (2.2) can be written as:

$$
\begin{array}{r}
y=X T T^{1} \beta+u=X T_{r} T_{r}^{1} \beta+X T_{p-r} T_{p-=r}^{1} \beta+u \\
=Z_{r} \alpha_{r}+Z_{p-r} \alpha_{p-r}+u
\end{array}
$$

where $Z_{r}=X T_{r}, \alpha_{r}=T_{r}^{1} \beta, Z_{p-r}=X T_{p-r}$, $\alpha_{p-r}=T_{p-r}^{1} \beta$.

The $\mathrm{n} \times p$ matrix of the principal components $Z=\left(z_{1}, z_{2}, \ldots z_{p}\right)=\left\lfloor Z_{r}, Z_{p-r}\right\rfloor \quad$ is obtained using $z_{i}=X t_{i}, i=1,2, \ldots p . \quad$ However, $Z_{p-r}$ contains PCs corresponding to near zero Eeigenvalues, and are thus discarded for the Principal Component Regression. The estimator of the parameters used in the Principal Component Regression and its true estimator in the light of model (2.2) are respectively given as:

$$
\begin{aligned}
& \hat{\alpha}_{P C R}=\left(Z_{r}^{1} Z_{r}\right)^{-1} Z_{r}^{1} y=\left(T_{r}^{1} X^{1} X T_{r}\right)^{-1} T_{r}^{1} X^{1} y \\
& \hat{\beta}_{P C R}=T_{r} \hat{\alpha}_{P C R}=T_{r}\left(T_{r}^{1} X^{1} X T_{r}\right)^{-1} T_{r}^{1} X^{1} y
\end{aligned}
$$

The mean and variance-covariance matrix of $\hat{\beta}_{P C R}$ are respectively obtained as:

$$
\begin{aligned}
& E\left[\hat{\beta}_{P C R}\right]=E\left[T_{r} \hat{\alpha}_{P C R}\right]=T_{r} E\left[\hat{\alpha}_{P C R}\right]=T_{r} T_{r}^{1} \beta \\
& D\left(\hat{\beta}_{P C R}\right)=D\left[T_{r} \hat{\alpha}_{P C R}\right]=\sigma_{r}^{2} T_{r}\left(T_{r}^{1} X^{1} X T_{r}\right)^{-1} T_{r}^{1}
\end{aligned}
$$

\section{A NEW APPROACH}

Theorem 1: The Principal Component Regression Estimator of a Linear Regression Model $y=X \beta+u$, where $y$ is $(n \times 1)$ vector for the observations of dependent variable; $X$ is $(n \times p)$ matrix of the observations of explanatory variables, $\beta$ is $(p \times 1)$ vector of regression coefficients $u$ is $(n \times 1)$ vector of the error terms assumed to multivariate normal distribution with mean zero and variance, $\sigma^{2} I_{n}$ which uses $r$ Principal Components, $r \leq p$, can be obtained as, $\hat{\beta}_{P C R}=\left(X^{1} X\right)^{-1} X^{1} \hat{y}_{r}$, where $\hat{y}_{r}$ is the predicted variable when $y$ is regressed on the $r$ principal components.

\section{Proof:}

Recall that the estimator of the parameters of the Principal Component Regression that uses $r$ Principal Components is given in (2.14) as:

$$
\hat{\alpha}_{P C R}=\left(Z_{r}^{1} Z_{r}\right)^{-1} Z_{r}^{1} y=\left(T_{r}^{1} X^{1} X T_{r}\right)^{-1} T_{r}^{1} X^{1} y
$$

Then, the predicted value of dependent variable becomes:

$$
\hat{y}_{r}=Z_{r} \hat{\alpha}_{P C R}=X T_{r}\left(T_{r}^{1} X^{1} X T_{r}\right)^{-1} T_{r}^{1} X^{1} y
$$

Multiplying both sides by $X^{1}$, (3.2) becomes:

$$
X^{1} \hat{y}_{r}=X^{1} X T_{r}\left(T_{r}^{1} X^{1} X T_{r}\right)^{-1} T_{r}^{1} X^{1} y
$$

But from (2.15), $\hat{\beta}_{P C R}=T_{r}\left(T_{r}^{1} X^{1} X T_{r}\right)^{-1} T_{r}^{1} X^{1} y$.

Therefore,

$$
X^{1} \hat{y}_{r}^{*}=X^{1} X \hat{\beta}_{P C R}
$$

Hence, it follows that

$$
\hat{\beta}_{P C R}=\left(X^{1} X\right)^{-1} X^{1} \hat{y}_{r}
$$

This completes the proof.

Theorem 2: Following from theorem (1), the mean, variance, bias and mean square error of true estimator of Principal Component Regression Parameters are respectively as:

$$
E\left(\hat{\beta}_{P C R}\right)=E\left\lfloor\left(X^{1} X\right)^{-1} X^{1} \hat{y}_{r}\right\rfloor=T_{r} T_{r}^{1} \beta
$$


(ii) $\quad D\left(\hat{\beta}_{P C R}\right)=D\left[\left(X^{1} X\right)^{-1} X^{1} \hat{y}_{r}\right]=\sigma_{r}^{2} T_{r}\left(T_{r}^{1} X^{1} X T_{r}\right)^{-1} T_{r}^{1}$

(iii) $\quad \operatorname{Bias}\left(\hat{\beta}_{P C R}\right)=\left(T_{r} T_{r}^{1}-I\right) \beta$

(iv) $\operatorname{MSEM}\left(\hat{\beta}_{P C R}\right)=\sigma_{r}^{2} T_{r}\left(T_{r}^{1} X^{1} X T_{r}\right)^{-1} T_{r}^{1}+\left(T_{r} T_{r}^{1}-I\right) \beta \beta^{1}\left(T_{r} T_{r}^{1}-I\right)^{1}$

Proof:

(i)

$$
\begin{aligned}
E\left(\hat{\beta}_{P C R}\right)=E\left[\left(X^{1} X\right)^{-1} X^{1} \hat{y}_{r}\right]= & \left(X^{1} X\right)^{-1} X^{1} E\left(\hat{y}_{r}\right) \\
= & \left(X^{1} X\right)^{-1} X^{1} E\left(Z_{r} \hat{\alpha}_{r}\right) \\
& =\left(X^{1} X\right)^{-1} X^{1} Z_{r} E\left(\hat{\alpha}_{r}\right) \\
& =\left(X^{1} X\right)^{-1} X^{1} X T_{r} E\left(\hat{\alpha}_{r}\right) \\
& =T_{r} T_{r}^{1} \beta
\end{aligned}
$$

(ii)

$$
\begin{aligned}
D\left(\hat{\beta}_{P C R}\right)=D & {\left[\left(X^{1} X\right)^{-1} X^{1} \hat{y}_{r}\right\rfloor } \\
& =\left(X^{1} X\right)^{-1} X^{1} D\left(\hat{y}_{r}\right) X\left(X^{1} X\right)^{-1} \\
& =\left(X^{1} X\right)^{-1} X^{1} D\left(Z_{r} \hat{\alpha}_{r}\right) X\left(X^{1} X\right)^{-1} \\
& =\left(X^{1} X\right)^{-1} X^{1} Z_{r} D\left(\hat{\alpha}_{r}\right) Z_{r}^{1} X\left(X^{1} X\right)^{-1} \\
& =\left(X^{1} X\right)^{-1} X^{1} X T_{r} \sigma_{r}^{2}\left(T_{r}^{1} X^{1} X T_{r}\right)^{-1} T_{r}^{1} X^{1} X\left(X^{1} X\right)^{-1} \\
& =\sigma_{r}^{2} T_{r}\left(T_{r}^{1} X^{1} X T_{r}\right)^{-1} T_{r}^{1}
\end{aligned}
$$

Consequently, the bias and the mean square error matrix (MSEM) follow from (3.6) and (3.7) as:

$$
\operatorname{Bias}\left(\hat{\beta}_{P C R}\right)=\left(T_{r} T_{r}^{1}-I\right) \beta
$$

$$
\begin{aligned}
& \operatorname{MSEM}\left(\hat{\beta}_{P C R}\right)= \\
& \sigma_{r}^{2} T_{r}\left(T_{r}^{1} X^{1} X T_{r}\right)^{-1} T_{r}^{1}+\left(T_{r} T_{r}^{1}-I\right) \beta \beta^{1}\left(T_{r} T_{r}^{1}-I\right)^{1}
\end{aligned}
$$

Thus, we observed that this new approach is simpler and easier to apply. Here, the PCs are used as regressors to predict the dependent variable. After which, we regressed the obtained fitted values on the original explanatory variables using Ordinary Least Square (OLS) estimator. The results obtained is theoretical the same as the conventional one even in term of the sampling properties of estimators.

\section{APPLICATIONS TO REAL LIFE DATA}

\subsection{Application to Longley Data}

Longley (1967) initially adopted this dataset in his study. It comprises of six independent variables and one dependent variable. Other authors that have applied the data include Walker and Birch (1988), Ayinde et al. (2015), Yasin and Murat (2016) and recently, Lukman and Ayinde (2018). Walker and Birch (1988) provided the scaled condition number of the data set as 43,275 , which shows the model suffers from severe multicollinearity. This finding agrees with the result in Table 4.1, where the variance inflation factor is greater than 10. Table 4.1 further shows that the results of the conventional principal component estimates $(\mathrm{r}=2)$ and the proposed are either the same or very close, and they return the same standard error. They are also more efficient than OLS estimator. 
International Journal of Engineering Research and Technology. ISSN 0974-3154, Volume 13, Number 7 (2020), pp. 1616-1622

(C) International Research Publication House. https://dx.doi.org/10.37624/IJERT/13.7.2020.1616-1622

Table 4.1: The regression output with Longley Data

\begin{tabular}{|c|c|c|c|c|}
\hline \multirow{3}{*}{ Parameters } & \multicolumn{4}{|c|}{ Estimators } \\
\hline & \multicolumn{2}{|c|}{ OLS } & \multirow{2}{*}{$\begin{array}{c}\text { PCR EST. } \\
\text { (CONVENTIONAL) } \\
\text { PC12 }\end{array}$} & \multirow{2}{*}{$\begin{array}{c}\text { PCR EST. } \\
\text { (NEW APPROACH) }\end{array}$} \\
\hline & EST & VIF & & \\
\hline$\beta_{1}$ & $\begin{array}{l}-3482258.63 \\
(\mathbf{8 9 0 4 2 0 . 3 8 )} \\
\text { P-value }=0.004\end{array}$ & & $\begin{array}{l}0.000014515 \\
(\mathbf{2 . 2 4 5 4 0 D - 0 6 )}\end{array}$ & $\begin{array}{l}6.95234 \\
(\mathbf{2 . 2 4 5 4 0 D - 0 6 )}\end{array}$ \\
\hline$\beta_{2}$ & $\begin{array}{l}15.06 \\
(\mathbf{8 4 . 9 1 )} \\
\text { P-value }=0.863\end{array}$ & 135.53 & $\begin{array}{l}0.00079584 \\
(\mathbf{0 . 0 0 0 1 1 4 5 6 )}\end{array}$ & $\begin{array}{l}0.00021828 \\
(\mathbf{0 . 0 0 0 1 1 4 5 6 )}\end{array}$ \\
\hline$\beta_{3}$ & $\begin{array}{l}-0.0358 \\
(\mathbf{0 . 0 3 3 5 )} \\
\text { P-value = } 0.313\end{array}$ & 1788.51 & $\begin{array}{l}-0.0026323 \\
(\mathbf{0 . 0 0 2 7 0 0 6 )}\end{array}$ & $\begin{array}{l}-0.0026321 \\
(\mathbf{0 . 0 0 2 7 0 0 6 )}\end{array}$ \\
\hline$\beta_{4}$ & $\begin{array}{l}-0.0511 \\
(\mathbf{0 . 2 2 6 1 )} \\
\text { P-value = } 0.826\end{array}$ & 399.15 & $\begin{array}{l}0.57053 \\
\mathbf{( 0 . 0 0 8 9 9 5 3 )}\end{array}$ & $\begin{array}{l}0.57053 \\
\mathbf{( 0 . 0 0 8 9 9 5 3 )}\end{array}$ \\
\hline$\beta_{5}$ & $\begin{array}{l}-2.0202 \\
(\mathbf{0 . 4 8 8 4 )} \\
\text { P-value = } 0.003\end{array}$ & 33.62 & $\begin{array}{l}-0.65725 \\
(\mathbf{0 . 1 8 1 2 1 )}\end{array}$ & $\begin{array}{l}-0.65724 \\
(\mathbf{0 . 1 8 1 2 1 )}\end{array}$ \\
\hline$\beta_{6}$ & $\begin{array}{l}-1.0332 \\
(\mathbf{0 . 2 1 4 2 )} \\
\text { P-value = } \mathbf{0 . 0 0 1}\end{array}$ & 3.5889 & $\begin{array}{l}0.53145 \\
(\mathbf{0 . 1 4 2 7 4 )}\end{array}$ & $\begin{array}{l}0.53146 \\
(\mathbf{0 . 1 4 2 7 4 )}\end{array}$ \\
\hline$\beta_{7}$ & $\begin{array}{l}1829.15 \\
\mathbf{( 4 5 5 . 4 8 )} \\
\text { P-value = } 0.003\end{array}$ & 758.98 & $\begin{array}{l}0.027786 \\
(\mathbf{0 . 0 0 4 2 6 1 )}\end{array}$ & $\begin{array}{l}0.024236 \\
\mathbf{( 0 . 0 0 4 2 6 1 1 )}\end{array}$ \\
\hline MSE & $7.92846 \mathrm{D}+11$ & & 0.053316 & 0.053316 \\
\hline
\end{tabular}

NOTE: The Eigenvalues of $X^{1} X: 2.76779 \mathrm{D}+12,7.03914 \mathrm{D}+09,1.16090 \mathrm{D}+07,2504761.02102,1738.35637,13.30921,1.17218 \mathrm{D}-07$ 


\subsection{Application to Gruber Data}

To further illustrate the performance of the new approach and the conventional method, we use the data discussed in Gruber (1998). This data set is on Total National Research and Development Expenditures - as a per cent of the gross national product by country from 1972 to 1986 comparing four (4) independent variables. It has then been widely analyzed in literature by many authors, including Akdeniz and Erol (2003), Li and Yang (2010), and Chang and Yang (2012). Table 4.2 gives a summary of the results.

Table 4.2: The regression output with Gruber Data

\begin{tabular}{|c|c|c|c|c|}
\hline \multirow{3}{*}{ Parameters } & \multicolumn{4}{|c|}{ Estimators } \\
\hline & \multicolumn{2}{|c|}{ OLS } & \multirow{2}{*}{$\begin{array}{c}\text { PCR EST. } \\
\text { (CONVENTIONAL) } \\
\text { PC123 }\end{array}$} & \multirow{2}{*}{$\begin{array}{c}\text { PCR EST. } \\
\text { (NEW APPROACH) }\end{array}$} \\
\hline & EST & VIF & & \\
\hline$\beta_{1}$ & $\begin{array}{l}0.692076 \\
(\mathbf{0 . 8 6 4 5 2 2 )} \\
\text { P-value }=0.46\end{array}$ & & $\begin{array}{l}-0.018174 \\
(\mathbf{0 . 0 2 8 5 1 3 )}\end{array}$ & $\begin{array}{l}-0.018173 \\
(\mathbf{0 . 0 2 8 5 1 3 )}\end{array}$ \\
\hline$\beta_{2}$ & $\begin{array}{l}0.625848 \\
(\mathbf{0 . 1 7 6 5 3 4 )} \\
\text { P-value }=0.016\end{array}$ & 6.91 & $\begin{array}{l}0.53588 \\
\mathbf{( 0 . 1 4 1 8 3 )}\end{array}$ & $\begin{array}{l}0.53588 \\
\mathbf{( 0 . 1 4 1 8 3 )}\end{array}$ \\
\hline$\beta_{3}$ & $\begin{array}{l}-0.115382 \\
(\mathbf{0 . 3 1 2 4 0 1 )} \\
\text { P-value }=0.727\end{array}$ & 21.58 & $\begin{array}{l}-0.034363 \\
\mathbf{( 0 . 1 1 8 1 )}\end{array}$ & $\begin{array}{l}-0.034362 \\
\mathbf{( 0 . 1 1 8 1 )}\end{array}$ \\
\hline$\beta_{4}$ & $\begin{array}{l}0.286602 \\
(\mathbf{0 . 2 2 6 8 9 4 )} \\
\text { P-value }=0.262\end{array}$ & 29.76 & $\begin{array}{l}0.2838 \\
\mathbf{( 0 . 0 3 1 3 0 5 )}\end{array}$ & $\begin{array}{l}0.2838 \\
(\mathbf{0 . 0 3 1 3 0 5 )}\end{array}$ \\
\hline$\beta_{5}$ & $\begin{array}{l}0.02564 \\
(\mathbf{0 . 1 7 0 1 1 3 )} \\
\text { P-value }=0.886\end{array}$ & 1.98 & $\begin{array}{l}0.21042 \\
(\mathbf{0 . 0 3 3 6 9 2 )}\end{array}$ & $\begin{array}{l}0.21042 \\
(\mathbf{0 . 0 3 3 6 9 2 )}\end{array}$ \\
\hline MSE & 0.95658 & & 0.036989 & 0.036989 \\
\hline
\end{tabular}

NOTE: The Eigenvalues of $X^{\prime} X: 312.9320,0.7536,0.0453,0.0372,0.0019$.

Estimating all the parameters of the model by their estimators in this example with $r$ chosen to be three as done by Chang and Yang (2012), the results obtained are as shown in Table 2. The results of the conventional estimator as reported by Chang and Yang (2012) are the same as the new approach. We also observed that the estimates obtained with Principal Component Estimator has smaller standard errors and MSE than that of OLS estimator, showing that the former is more efficient. We can see that the new approach is applicable in practice.

\section{CONCLUSION}

The paper has proved another technique of using Principal Component Regression to address the multicollinearity problem in the linear regression model. The method provided gives the same results with the conventional method in terms of sampling properties of estimators and has the advantages of computation ease. The Principal Component Regression Estimator is more efficient than the OLS estimator. Two numerical examples support these findings. 
International Journal of Engineering Research and Technology. ISSN 0974-3154, Volume 13, Number 7 (2020), pp. 1616-1622

(C) International Research Publication House. https://dx.doi.org/10.37624/IJERT/13.7.2020.1616-1622

\section{REFERENCES}

[1] Abdul-Wahab, S. A., Bakheit, C. S. and Al-Alawi, S. M., (2005). Principal component and multiple regression analysis in modelling of ground- level ozone and factors affecting its concentrations. Environmental Modelling and Software 20, 12631271.

[2] Akdeniz, F. and Erol, H. (2003). Mean squared error matrix comparisons of some biased estimators in linear regression. Communication in Statistics Theory and Methods, 32:2389-2413.

[3] Ali S. and Robert, F. L. (1998). Some Cautionary Notes on the Use of Principal Components Regression. The American Statistician, 52 (1), 15-19.

[4] Ayinde, K., Lukman, A. F. and Arowolo, O.T. (2015). Robust regression diagnostics of influential observations in linear regression model. Open Journal of Statistics, 5, 1-11.

[5] Ayinde, K., Lukman A. F., Samuel, O. O. and Attah, O. M. (2018). Some New Adjusted Ridge Estimators of Linear Regression Model. International Journal of Civil Engineering and Technology, 9(11), 2838-2852.

[6] Batah, F. M., Ozkale, M. R. and Gore, S. D. (2009). Combining unbiased ridge and principal component regression estimators. Communication in Statistics Theory and Methods, 38:2201-2209.

[7] Chang, X. and Yang, H. (2012). Combining twoparameter and principal component regression estimators. Stat. Papers, 53:549-562.

[8] Chatterjee, S and Hadi, A. S. (2006). Regression Analysis by Example (Fourth Edition).

[9] Fomby, T. B., Hill, R. C., and Johnson, S.R.(1984). Advanced Econometric Methods. NY, Springer Verlag.

[10] Gruber, M.H.J. (1998) Improving efficiency by shrinkage: the James Stein and ridge regression estimators. Marcel Dekker, New York.

[11] Gujarati, D. N. (2005). Basic Econometrics, McGrawHill, New York.

[12] Lee, H. Park, Y.M. and Lee, S. (2015). Principal Component Regression by Principal Component Selection. Communications for Statistical Applications and Methods, 22, (2), 173-180. DOI: http://dx.doi.org/10.5351/CSAM.2015.22.2.173.

[13] Hoerl, A. E. and Kennard, R. W. (1970). Ridge regression: biased estimation for nonorthogonal problems. Technometrics, 12(1):55-67.

[14] Hotelling, H. (1933). Analysis of a complex of statistical variables into principal components. Journal of Educational Psychology, 24, 417-441, and 498-520.

[15] Kibria, B. M., (2003). Performance of some new ridge regression estimators. Communications in StatisticsSimulation and Computation, 32 (2) (2003), 419-435

[16] Maddala, G.S. (1988) Introduction to Econometrics, Macmillan, New York.
[17] Massy, W. F. (1965). Principal components regression in exploratory statistical research. Journal of the American Statistical Analysis, 60:234-266.

[18] Naes, T. and Marten, H. (1988). Principal Component Regression in NIR analysis: View points, Background Details Selection of components. Journal of Chemometrics, 2, $155-167$.

[19] Constantin, C. (2014). Principal Component Analysis A Powerful Tool in Computing Marketing Information. Bulletin of the Transilvania, University of Brasov,7 (56), 2.

[20] Kaiser, H. F. (1960). The application of electronic computers to factor analysis. Educational and Psychological Measurement, 20, 141-151.

[21] Liu, K. (1993). A new class of biased estimate in linear regression. Communication in Statistics Theory and. Methods, 22:393-402.

[22] Li, Y. and Yang, H. (2010) A new stochastic mixed ridge estimator in linear regression model. Stat. Pap. 51:315-323

[23] Longley, J.W. (1967) An appraisal of least squares programs for electronic computer from the point of view of the user. Journal of American Statistical Association, 62: 819-841.

[24] Lukman, A. F., Ayinde, K., Aladeitan, B. B., Rasak, B. (2020). An Unbiased Estimator with Prior Information. Arab Journal of Basic and Applied Sciences, 27:1, 4555.

[25] Lukman, A. F., Ayinde, K., Binuomote, S. and Onate, A. C., (2019). Modified ridge-type estimator to combat multicollinearity: Application to chemical data. Journal of Chemometrics, e3125. https://doi.org/10.1002/cem.3125

[26] Lukman, A. F. and Ayinde, K. (2018). Detecting Influential Observations in Two-Parameter Liu-Ridge Estimator. Journal of Data Science, 16(2), 207-218.

[27] Lukman, A. F., Ayinde, K., Okunola, A. O., Akanbi, O. B. and Onate. C. A. (2018). Classification-Based Ridge Estimation Techniques of Alkhamisi Methods. Journal of Probability and Statistical Sciences. 16(2), 2018, 165-181.

[28] Ozkale, M. R. (2009). Principal components regression estimator and a test for the restrictions. Statistics, 43:541-551.

[29] Walker, E. and Birch, J. B. (1988). Influence Measures in Ridge Regression. Technometrics, 30(2), 221- 227.

[30] Wold, Herman (1985). "Partial least squares". In Kotz, Samuel; Johnson, Norman L. (eds.). Encyclopedia of statistical sciences. 6. New York: Wiley. 581-591.

[31] Yasin, A. and Murat, E. (2016). Influence Diagnostics in Two-Parameter Ridge Regression. Journal of Data Science, 14, 33-52.

[32] Kibria, G. B. M. and Lukman, A. F. (2020). A New Ridge-Type Estimator for the Linear Regression Model: Simulations and Applications. Scientifica. https://doi.org/10.1155/2020/9758378. 